\title{
Reflective writing: Factors that influence the successful transition of nursing students entering into their second semester of a $\mathrm{RN}-\mathrm{ABSN}$ program
}

\author{
Debra R. Wallace * \\ California State University of Northridge, United States
}

Received: March 12, 2016

Accepted: May 10, 2016

Online Published: May 27, 2016

DOI: $10.5430 /$ jnep.v6n10p43

URL: http://dx.doi.org/10.5430/jnep.v6n10p43

\begin{abstract}
Objective: Identify factors influencing the successful transition of nursing students entering into their second semester of a RN-ABSN program.

Background: Newly graduate registered nurses (RNs) are able to enter practice within weeks of graduation as fully licensed RNs. An inadvertent effect of this transition is placing new graduates into an environment that demands safe, effective and quality care. Identifying factors that influence the successful transition of nursing students entering into the second semester of an ABSN (Accelerated Bachelor of Science Nursing) program sets off ones actions, increases awareness and understanding, and promotes the development of personal experiences by means of reflective journaling. Reflective journal rubrics (personal narrative of storytelling) help to fortify the successful transformation to practice by allowing self-reflection and encourage the reconceptualization of the problem situations. Reflective journals illuminate performance expectancies and can diminish misperceptions around role. The reflective journal rubric for assessing RN performance, focused on reflective writing. The tool was developed using the modified version of written exercises by Freshwater, Taylor and Sherwood for active learning concepts used in the classroom. Reflective journaling incorporates the application of concepts and leads to increase mastery and retention of content. Additionally, it identifies important themes and offers opportunities for students to discuss essential topics for a smooth transition into their first and second semester.

Methods: A group of seventeen ABSN students in the second semester medical surgical clinical were required to participate in the reflective journaling at the beginning and end of their experiences in training as a part of their preparation for a clinical rotation. Nurse educators, read the reflective journals to gain insight into the participants' experience and then coded to highlighted themes. The journals were evaluated with the reflective practices of Freshwater, Taylor and Sherwood who have proposed the use of the term "art" pertinent in the context of reflective journaling in nursing. Qualitative content analysis was deemed complete when agreement was reached regarding major themes. Dependability was achieved by the researchers using the participants' own words to support the themes and conclusions. Data Collection: IRB approval was obtained. 17 students participated in the study and identifying themes from approximately 17 students over the past 2 years. The self-reflection rubric contained open-ended, short write-in items. Responses were anonymous. No names, email addresses, nor computer IP addresses were collected.

Results: Seventeen journals were analyzed. Students are using critical reflection to improve practice, especially with respect to Freshwaters statement 'thinking about thinking'. The key outcomes indicated that reflective journals assist students to focus on their clinical learning during the coaching point. These following themes emerged: my preceptor was knowledgeable about nursing practice, therapeutic touch, confidence level, prioritization of patient care, caring, communication, six rights of medication administration, holistic approach and skills.

Conclusions: This study heightens most discussions on the use of reflective journals validating previous information defined in
\end{abstract}

*Correspondence: Debra R. Wallace; Email: Debra.Wallace@ csun.edu; Address: California State University of Northridge, United States. 
the literature with the advantages of utilizing journals in terms of fostering and stimulating reflection type to enhance first-hand learning in the nursing student's clinical practice.

Key Words: Reflective journals, Clinical practice, Qualitative study, Reflective practice in nursing

\section{INTRODUCTION}

New graduates must master their professional skills despite increasing obligations, responsibilities and challenges. The reflective journal is an examination of personal thoughts and actions. A study by Asselin (2011) demonstrates the effects of reflective practice on RN-to-BSN students as it changes the nurses' practice perspectives and actions. ${ }^{[1]}$

Reflective practice is a journey of self-discovery that leads to better practitioners. ${ }^{[2]}$ A study by Bradbury-Jones et al. (2009) shows an increase in student's self-awareness after the implementation of reflective practice. ${ }^{[3]}$ Some nurses even describe reflecting with their peers though out the work day. This collegial support aided them by increasing their confidence in their decision making process.

Roets (2013) stated reflective practice signifies a determination to continually assess and examine circumstances, and may be vital to individual learning. ${ }^{[4]}$ For new graduates this means focusing on how they interact with their preceptors and with the professional environment to obtain a clearer picture of their own performance. Reflective practice can be used to bridge the theory-practice gap by encouraging examination, exploration and connections. ${ }^{[5,6]}$

\subsection{Aims}

The aim of this study was to demonstrate factors through reflective practice how nursing students interact with their colleagues and build on their knowledge established during their medical surgical rotation.

\subsection{Reflective writing and reflective practice in clinical practice}

Reflection allows individuals to better understand patient problems through reflective writing and reflective practice in the clinical setting. Wallace \& Boller (2014) stated there is a promotion of confidence, the generation of perception and comprehension, along with critical thinking and problem solving by utilizing reflective journaling. ${ }^{[7]}$ Reflective writing also permits nursing students to clarify proficient goals, express feelings, and assimilate collaborative-learning styles. Furthermore, by learning specific competencies, Student nurses are able to achieve clinical competencies through insightful wisdom and reflective practice. Reflective practice is an approach used to reach deeper meaning or additional understanding of ideas and knowledge. ${ }^{[8]}$ Reflective writing provides an opportunity for new Student nurses to redirect on their clinical practice by writing about the encounters.

Journal writing is a tool that allows writers to integrate new concepts. Goldenhar and Kues (2006) conducted a study at the University of Cincinnati College of Medicine that required students in the Geriatric Medical Student Scholars program to journal about their practices. The results showed that reflective writing provided both personal and professional learning. ${ }^{[9]}$ Many studies have characterized similar advantages of applying reflective writing to their clinical experiences. In a study by Asselin (2011) and Beam et al. (2010), participants described added insights to their experiences by using reflective writing. ${ }^{[1,10]}$ Freshwater et al. (2008) used to significant meaning and further understanding of the concept of evidence-based practice and experiences. ${ }^{[6]}$ Langley \& Brown (2010) assessed reflective journals for graduate nursing education and attained results that address both strengths and weaknesses of reflective writing. ${ }^{[11]}$ Daroszewski, Kinser, and Lloyd (2004) used online reflective journaling with advanced practice nursing students to enhance their clinical learning including applying core principals to different facets of practice, creating opportunities for mentoring, fostering critical thinking, and facilitating change and socialization into advanced practice. ${ }^{[12]}$

According to Wright et al. (2007), reflective writing allows one to generate learning that may trigger deeper connotation about the implication of their clinical experiences. ${ }^{[13]}$ The numerous benefits of journal writing allow students to not only review the day's activities, but also uncover emotions accompanying clinical experiences, and the knowledge and understanding surrounded in the clinical setting. Moreover, clinical faculty can assess the student's entries to evaluate Student nurses' reasoning, problem solving, and to offer learning opportunities for the Student nurses' learning process. ${ }^{[14]}$

Thorough reflective writing is a skill that benefits new Student nurses in at least two important ways: (1) the student nurses gain knowledge concerning their specific medical surgical patient population and how to care for their patients'; and (2) they increase their own individual learning needs. The following sections describe the student's reflective writing. A reflective writing journal rubric was created as a part of the course syllabi. 


\subsection{Theoretical framework}

Philosopher Donald Schon is best known for his work with the development of reflective practice and learning systems. This interest was mirrored in his exploration of professional's ability to "Think on our feet". This reflection-in-action model this holistic framework embraces an exploration of an individual's experience and connecting to one's feelings. ${ }^{[15]}$ Reflective practice is a powerful process that contributes to the making of a quality expert nurse (see Figure 1). Reflective practice empowers nurses in both the educational and professional realms. McLeod (1996), $\mathrm{PhD}$, an expert in reflective practice argues that there are three distinct processes for performance improvement and offers three assumptions concerning the development of expertise. ${ }^{[16]}$

(1) Noticing-a conscious awareness that can be enhanced. First stage awareness of uncomfortable feelings and thoughts such as experience of surprise, inner discomfort and judgmental reflectivity.

(2) Reflection-past experiences and understanding, plus the particulars of the present context with the practitioner deeply immersed in the unfolding situation. Second stage critical analysis of the situation, reflection and criticism, openness to new information and perspectives; resolution

(3) Action/Intervening-selecting from a range of options. Third stage development of new perspective, establishing continuity of self with past, present and future, deciding whether or not to take action, transformation, cognitive and affective behavioral changes.

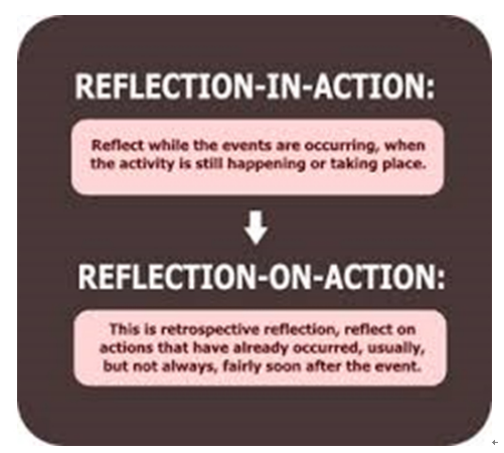

Figure 1. Schon's Model on Reflective Practice

\section{MethodS}

The group of seventeen ABSN students in the second semester medical surgical clinical were required to participate in the reflective journaling at the beginning and end of their experiences in training as a part of their preparation for a clinical rotation. A descriptive focus and emergent design methodology was utilized. The self-reflection journal form was developed by the course instructor and reviewed by five other experienced nurse educators to support content validity. (see Figure 2). Nurse educators, read the reflective journals to gain insight into the participants' experience and then coded to highlighted themes. The journals were evaluated using a qualitative method centered on the reflective practices of by Freshwater, Taylor and Sherwood who have proposed the use of the term "art" pertinent in the context of reflective journaling in nursing. Qualitative content analysis was deemed complete when agreement was reached regarding major themes. Dependability was achieved by the researchers using the participants' own words to support the themes and conclusions.

\begin{tabular}{|l|}
\hline My activities/interactions or interventions with patients, staff, and/or \\
family \\
\hline $\begin{array}{l}\text { Feelings, reactions, \& insights to specific events or patient/family/staff } \\
\text { experiences }\end{array}$ \\
\hline Relate reading/lecture/theory to this clinical experience \\
\hline $\begin{array}{l}\text { What I learned \& areas for future learning } \\
\text { altered my definition of caring? }\end{array}$ \\
\hline What would I have done the same? \\
\hline
\end{tabular}

Figure 2. Self-reflection Questionnaire

\section{Data collection}

IRB approval was obtained. Second semester nursing students participated in the study and identifying themes from approximately seventeen students over the past 2 years. The self-reflection journal form contained open-ended, short 
write-in items. Responses were anonymous. No names, email addresses, nor computer IP addresses were collected.

\section{FINDINGS AND DISCUSSION}

\subsection{Results}

Seventeen journals were analyzed. Students were using critical reflection to improve practice, especially with respect to Freshwaters statement "thinking about thinking". All seventeen students were full time at the university. Keys themes emerged consistent with. Most statements were found in the category of "caring, communication, therapeutic touch and patient care". Fewest in the category were "reading my medical surgical textbook".

\subsection{Discussion}

The aim of this study was to describe how nursing students reflected on their knowledge established during their medical surgical rotation. The discussion will show how students reflective writing journals improved their clinical knowledge.

\subsection{Knowledge based medical surgical clinical practice}

The second semester nursing student's reflective writing results show that students largely expressed "My nursing preceptor was knowledgeable about nursing practice" from the first question.

Important Reaction and Insights. Respondents were asked: Feelings, reactions and insights to specific events or patient/family staff experiences during the advance medical surgical experience? The responses described my nursing preceptor was knowledgably about nursing practice, six rights to medication administration and communication as the most important.

My nursing preceptor was knowledgeable about nursing practice. The description my nursing preceptor was knowledgeable about nursing practice as an important reaction to their learning (see Table 1). The students documented the necessity to develop improved nursing skills and the need to take care of the patient.

Six rights to medication administration. Respondent's perceptions towards the need to follow the six rights of medication administration underscore the need for preventing harm to the patient (see Table 1). Barbour (2013) concluded that reflection is a method of formalizing informal learning and development that has the potential to impact patient care and to refine good practice. ${ }^{[2]}$

Communication. The communication among nurses and patients which illustrated the significance of communication in healthcare (see Table 1). It was willingly apparent that the students recognized the importance of good communication skills. Responses also demonstrated the beneficial role which good communication provides.

From the comments, three areas contributed to decisions regarding "Feelings, reactions and insights to specific events" provided during the advanced medical surgical experience. Three themes emerged from the student responses:

(1) The need for knowledgeable nursing preceptors to facilitate patient care services for the medical surgical clinical rotation.

(2) Need to improve six rights of medication administration improved safety for patient care provided in the medical surgical clinical rotation.

(3) Need to provide good communication skills in the delivery of patient care for the medical surgical clinical rotation

Respondents were asked: How has this advanced medical surgical clinical experience added to my understanding of nursing? The responses described increased confidence level, therapeutic touch, holistic approach, prioritization of care and my definition of nursing as adding to my understanding of nursing.

Confidence level. From the collective responses (see Table 2) a key to adding to my understanding of nursing was confidence. All respondent identified that improved confidence was viewed as an important understanding of nursing in the medical surgical clinical experience.

Therapeutic touch. Therapeutic though in the advanced medical surgical clinical setting was on identified as adding to my understanding of nursing challenging and very different from other skills that the nursing students had practiced in the medical surgical clinical setting. Respondents pointed to the need for therapeutic touch as comforting to the patient and provided dignity and respect which helped the patient respond more effectively against illness.

Holistic approach. The basic fundamentals of nursing students' knowledge development include guidance in managing a holistic approach that is patient centered, and collaborative. Today, nurses are faced with a healthcare environment that is relentlessly changing. Patients appear with acute and complex healthcare concerns, and hospitals depend on nurses to deliver a wide array of health services. These include primary and preventative care, along with educating patients on avoiding injury which may lead to extensive hospitalization and nursing home care. The American holistic nursing association defines "all nursing practice that has healing the whole person as its goal". ${ }^{[17]}$ It is a practice which acknowledges practicing integrating self-care, self-responsibility, spirituality, and reflection for the patient. The respondents reported 
that to be a nurse you need to use holistic approach and adapt the care for the patient's individual needs (see Table

2). This testimonial by the nurses is consistent with Flo- rence Nightingale's vision for healing in a study by Dossey (2010). ${ }^{[18]}$

Table 1. Feelings, reactions and insights to specific events or patient/family/staff experiences during this advanced medical surgical experience?

\begin{tabular}{|c|c|c|}
\hline Category & Number of Responses & Respondent Answers \\
\hline $\begin{array}{l}\text { My nursing preceptor } \\
\text { was knowledgeable } \\
\text { about nursing practice }\end{array}$ & $11(65 \%)$ & $\begin{array}{l}\text { "my nurse was kind and knowledgeable about nursing practice” } \\
\text { "I really enjoyed seeing the different nursing styles and feel I picked up something from } \\
\text { everyone" } \\
\text { "my nurse gave the patient comfort by talking in a calm manner" } \\
\text { " my nurse was very welcoming \& worked with me and helped me learn" } \\
\text { "my nurse helped me communicate with a patient that was nonverbal and mentally } \\
\text { challenged" } \\
\text { "my nurse worked with me and made me feel like I took a huge step closer to having the } \\
\text { knowledge and training of a working RN" } \\
\text { "my nurse was excited to be a teacher for the day and taught me about the need for experience } \\
\text { caring for patients" } \\
\text { "my nurse made me feel like I was in control and supported my learning” } \\
\text { "my nurse showed me techniques for waking up patients so that they would talk to us “ } \\
\text { " my nurse had a good report with the doctor" } \\
\text { "my nurse was extremely observant with the patients and knew all about the medications" } \\
\text { "my nurse helped me calm the confused patient while doing a dressing change” }\end{array}$ \\
\hline $\begin{array}{l}\text { Six Rights to } \\
\text { Medication } \\
\text { Administration }\end{array}$ & $4(24 \%)$ & $\begin{array}{l}\text { "I realized that following the } 6 \text { rights of medication administration prevented a medication } \\
\text { error" } \\
\text { "Familiarization with medications and their interactions helped me understand the importance } \\
\text { of pharmacology and assessing the patient" } \\
\text { "Having the patient understand what the medication is used for and the side effects and having } \\
\text { the patient communicate this knowledge" }\end{array}$ \\
\hline Communication & $3(18 \%)$ & $\begin{array}{l}\text { "I experienced conflict in communication among nurses working in the observation unit. } \\
\text { These patients are closely monitored and the objectives for care constantly change and how } \\
\text { important it is to value the needs of each patient." } \\
\text { "I understand why it was important to communicate to the patient with anxiety. } \\
\text { Communicating to the patient lessened the anxiety" } \\
\text { "I felt the power of listening to the patient communicate and just being present with them } \\
\text { reinforced how broad the scope of nursing is" }\end{array}$ \\
\hline
\end{tabular}

Prioritization of patient care. Prioritization of patient care was described as the need to develop critical thinking about the plan of care in the medical surgical clinical setting. The respondents reported that the importance of knowing how to prioritize patient care and understand time management would be key in learning medical surgical nursing.

My definition of caring. The last theme to adding to my understanding of nursing was described as the need for caring for patients in the medical surgical clinical setting. The definition of caring was supported by the statements increased the nursing students scope of knowledge and opportunity of caring in the nursing field (see Table 2).

It was apparent from the reflective writing statements that without practice in the advanced medical surgical clinical setting nursing students have insufficient information about patient care issues, a finding that is acknowledged in the clinical literature.

In summary, five themes developed from the students responses:

(1) Need for enhanced confidence level to assist care provided in the medical surgical clinical area.

(2) Need to increase therapeutic touch for better-quality of care provided in the medical surgical clinical area.

(3) The need to improve holistic approach that gives patients healing and a facilitator in the therapeutic process.

(4) Improve on prioritization of patient care of health care in the medical surgical clinical setting.

(5) Need to improve my definition of caring to patient's increases health care. 
Table 2. How has this advanced medical surgical clinical experience added to my understanding of nursing? Has it altered my definition of caring?

\begin{tabular}{|c|c|c|}
\hline Category & Number of Responses & Respondent Answers \\
\hline Confidence Level & $2(12 \%)$ & $\begin{array}{l}\text { "This semester my confidence level has exceeded from last semester" } \\
\text { "Every day that I get more experience makes me feel more comfortable and confident to care for } \\
\text { the patients" }\end{array}$ \\
\hline Therapeutic Touch & $4(24 \%)$ & $\begin{array}{l}\text { "A simple use of therapeutic touch is also comforting to the patients" } \\
\text { "Providing comfort, dignity and respect helps patients respond more effectively against illnesses" } \\
\text { "The patients in the stroke rehabilitation really wanted to talk about their progress and how } \\
\text { important this was to share with me" } \\
\text { "The importance of siting \& listening with the family of a patient in an unstable state and letting } \\
\text { them cry and talk" }\end{array}$ \\
\hline Holistic Approach & $3(18 \%)$ & $\begin{array}{l}\text { "To be a nurse you need to use the holistic approach and adapt the care for the patients individual } \\
\text { needs" } \\
\text { "I still believe that nursing is a multifaceted profession and the nurse must be efficient to make } \\
\text { sure all aspects of care are met before you leave for the day" } \\
\text { "The patient should always be the center of care and I should attend to all of their needs" }\end{array}$ \\
\hline $\begin{array}{l}\text { Prioritization of } \\
\text { Patient Care }\end{array}$ & $3(18 \%)$ & $\begin{array}{l}\text { "You need to think critically about the plan of care for your patient" } \\
\text { "The importance of knowing how to prioritize patient care and understand time management" } \\
\text { "Broadened my awareness of how crucial nurses are in catching and stopping changes in health } \\
\text { conditions of their patients" }\end{array}$ \\
\hline $\begin{array}{l}\text { My definition of } \\
\text { caring }\end{array}$ & $4(24 \%)$ & $\begin{array}{l}\text { "My definition of caring remains the same, though I see how all of the time restraints and all the } \\
\text { requirements can make it difficult" } \\
\text { "My definition of caring has not only been altered but expanded. Caring is not only being kind to } \\
\text { the person through words but also caring through actions" } \\
\text { "This has not altered my definition of caring actually increased my scope of knowledge and } \\
\text { opportunity of caring in the nursing field" } \\
\text { "My definition of caring continues to evolve. What was once a abstract idea based on theory has } \\
\text { taken on a new meaning with my clinical experience and application of nursing" }\end{array}$ \\
\hline
\end{tabular}

Table 3. What would I have done differently for this advanced medical surgical clinical experience?

\begin{tabular}{|c|c|c|}
\hline Category & $\begin{array}{l}\text { Number of } \\
\text { Responses }\end{array}$ & Respondent Answers \\
\hline $\begin{array}{l}\text { Read my medical } \\
\text { surgical textbook }\end{array}$ & $2(12 \%)$ & $\begin{array}{l}\text { "In a perfect world I would read } \\
\text { my textbook more and practice } \\
\text { writing nursing care plans" }\end{array}$ \\
\hline Skills & $6(35 \%)$ & $\begin{array}{l}\text { "I would focus more on the } \\
\text { symptoms of the patient and } \\
\text { organize my assessment based } \\
\text { on the patient's disease process" } \\
\text { "I would have prepared for } \\
\text { medication administration better } \\
\text { to prevent errors" } \\
\text { "I would do more skills when the } \\
\text { opportunities were available" }\end{array}$ \\
\hline Caring & $2(12 \%)$ & $\begin{array}{l}\text { "Caring for the patient helped } \\
\text { me understand their needs } \\
\text { and increase my critical thinking } \\
\text { skills" }\end{array}$ \\
\hline $\begin{array}{l}\text { Communication and } \\
\text { interpersonal skills }\end{array}$ & $5(29 \%)$ & $\begin{array}{l}\text { "My patient was combative. I } \\
\text { would have communicated } \\
\text { differently with this patient" } \\
\text { "I would communicate more } \\
\text { with my preceptor so that her job } \\
\text { was not harder teaching me" } \\
\text { "I would explain to the patient } \\
\text { using simple words when } \\
\text { teaching at the bedside" }\end{array}$ \\
\hline
\end{tabular}

The nursing students were asked: If you could change something about the advanced medical surgical clinical experience what would it be? The respondents described read my medical surgical textbook, skills, caring and better communication and interpersonal skills as needed advanced medical surgical changes.

Read my medical surgical textbook. It was quite evident that the respondents that increased time reading the medical surgical textbook should be encouraged throughout the advance medical surgical clinical experience to decrease role strain and practice writing nursing care plans for students in the advanced medical surgical clinical setting (see Table 3). This finding is consistent with the Institute of Medicine's key messages that suggest nurses must take a leadership role in to ensure that the nursing profession is responding to the current healthcare system with efficiency, quality and safety, and is focused on being patient centered. ${ }^{[19]}$

Skills. The need for increased skill practice was supported by responses which supported the need to expand the current practices for students in the advanced medical surgical clinical setting. This is consist with the recent study by Spetz et al. (2013) that indicates when nurses respond effectively using their higher levels of training and education, nurses 
can deliver high-quality primary care. ${ }^{[20]}$

Caring. The need for caring in the current advanced medical surgical clinical setting was stated by the students (see table 3 ). One of the responses included, "the need for caring for the patient helped me understand their needs and increased my critical thinking skills." This statement supports the evidence based literature that nurses knowledge increased availability of advanced medical surgical clinical settings improves patient satisfaction. ${ }^{[20]}$

Communication and interpersonal skills. The students reported pertained to the need for increased communication with my preceptor and the use of interpersonal skills to help calm a combative patient to give better quality health care in the advanced medical surgical setting. ${ }^{[21]}$

In summary, four recommendations developed from the participant responses:

(1) Need to increase time reading medical surgical textbook improved efficacy of care provided in the advanced medical surgical clinical setting.

(2) The need to expand the skill set of practice that gives patients better-quality health care in the advanced medical surgical clinical setting.
(3) Need to improve caring at the bedside to assist patient care provided in the advanced medical surgical setting.

(4) The need to improve communication marketing and interpersonal skills of health care provided in the advanced medical surgical clinical setting.

\section{Conclusions}

The findings suggest that self-reflection in the advanced medical surgical clinical setting has an encouraging effect on learning for the nursing students. It represents the capability to familiarize the students with the clinical situation prior to clinical practice at the hospital. Moreover, it allows students to have more opportunities of practicing their critical thinking, basic nursing skills, communication and teamwork, according to the learning goals. In order to meet such goals, the study supports the discussion on the use of reflective writing endorsing what has already been described in the literature with respect to reflective writing journals in terms of fostering and motivating reflection type to enhance first-hand learning in the nursing student's clinical practice.

\section{CONFLICTS OF INTEREST DisClOSURE}

The authors declare that there is no conflict of interest.

\section{REFERENCES}

[1] Asselin ME. Using Reflection Strategies to Link Course Knowledge to Clinical Practice: The RN-to-BSN Student Experience. Journal of Nursing Education. 2011; 50(3): 125-133. PMid:21210605. http://dx.doi.org/10.3928/01484834-20101230-08

[2] Barbour JF. The Making of a Butterfly: Reflective Practice in Nursing Education. International Journal for Human Caring. 2013; 17(3): 7.

[3] Bradbury-Jones C, Hughes SM, Murphy W, et al. A New Way of Reflecting in Nursing: The Peshkin Approach. Journal of Advanced Nursing. 2009; 65(11): 2485-2493. PMid:19832751. http: //dx.doi.org/10.1111/j.1365-2648.2009.05144.x

[4] Roets L. Learning through reflection: Supervising DRC master's degree students within the open distance and learning context. Journal of Nursing Education and Practice. 2013; 3(10): 139-149. http://dx.doi.org/jnep.v3n10p139

[5] Benner P, Sutphen M, Leonard V, et al. Educating nurses: A call for radical transformation. San Francisco, CA: Jossey-Bass; 2010.

[6] Freshwater D, Taylor BJ, Sherwood G. International Textbook of Reflective Practice in Nursing. Oxford, UK: Wiley-Blackwell; 2008.

[7] Wallace D, Boller J. New nurse practitioner competencies: Skill development and reflective writing rubrics. Journal for Nurse Practitioners. 2014; 10(7): e13-e21. http://dx.doi.org/10.1016/j .nurpra.2014.04.018

[8] Cook DA. Learning and Cognitive Styles in Web-based Learning: Theory, Evidence, and Application. Academic Medicine. 2005; 80(3): 266-278. http://dx.doi.org/10.1097/00001888-200 503000-00012

[9] Goldenhar LM, Kues JR. Effectiveness of a Geriatric Medical Student Scholars Program: A Qualitative Assessment: Geriatric Medi- cal Student Scholar's Program Assessment. Journal of the American Geriatrics Society. 2006; 54(3): 527-534. PMid:16551324. http://dx.doi.org/10.1111/j.1532-5415.2005.00617.x

[10] Beam RJ, O'Brien RA, Neal M. Reflective practice enhances public health nurse implementation of nurse-family partnership. Public Health Nursing. 2010; 27(2): 133-139.

[11] Langley ME, Brown ST. Perceptions of the use of reflective journals in online graduate nursing education. Nursing Education Perspectives. 2010; 31(1): 12-17. PMid:20397474.

[12] Daroszewski EB, Kinser AG, Lloyd SL. On-line directed journaling in advanced practice clinical nursing education. The Journal of Nursing Education. 2004; 43(4): 175-180. PMid:15098912.

[13] Wright KA, Powers SL, Ali M. The role of reflective journaling in physician assistant education. J Physician Assist Educ. 2007; 18(4): 20-26. http://dx.doi.org/10.1097/01367895-20071 8040-00005

[14] Lasater K, Nielsen A. Reflective Journaling for Clinical Judgment Development and Evaluation. Journal of Nursing Education. 2009; 48(1): 40-44. http://dx.doi.org/10.3928/01484834-20090 101-06

[15] Schön D. The Reflective Practitioner. How professionals think in action. New York, NY: Basic Books; 1983.

[16] Mann K, Gordon J, MacLeod A. Reflection and Reflective Practice in Health Professions Education: A Systematic Review. Advances in Health Sciences Education. 2009; 14(4): 595-621. PMid: 18034364 http://dx.doi.org/10.1007/s10459-007-9090-2

[17] American Holistic Nurses' Association. Description of Holistic Nursing. Flagstaff (AZ): American Holistic Nurses Association; 1998. 
[18] Dossey B. Florence nightingale's vision for health and healing. Journal of Holistic Nursing: Official Journal of the American Holistic Nurses' Association. 2010; 28(4): 221-224. PMid:21149553. http://dx.doi.org/10.1177/0898010110383111

[19] Health Resources and Services Administration. Projecting the Supply and Demand for Primary Care Practitioners through 2020. http://bhpr.hrsa.gov/healthworkforce/supplyde mand/usworkforce/primarycare/. Published November 2013.
Accessed February 11, 2016.

[20] Spetz J, Parente ST, Town RJ, et al. Scope-of-practice Laws for Nurse Practitioners Limit Cost Savings That Can Be Achieved in Retail Clinics. Health Affairs (Project Hope). 2013; 32(11): 19771984. PMid:24191089. http://dx.doi.org/10.1377/hlthaff .2013 .0544

[21] Riley JB. Communication in Nursing, 7th ed. St. Louis: Mosby; 2004. 